\title{
Communication \\ Surface Properties of Plasma-Activated Chitosan Foils
}

\author{
Konrad Terpiłowski (10) and Emil Chibowski *
}

check for

updates

Citation: Terpiłowski, K.; Chibowski,

E. Surface Properties of

Plasma-Activated Chitosan Foils.

Colloids Interfaces 2022, 6, 6. https:/ /

doi.org/10.3390/colloids6010006

Academic Editor: Marta Krasowska

Received: 9 October 2021

Accepted: 13 December 2021

Published: 17 January 2022

Publisher's Note: MDPI stays neutral with regard to jurisdictional claims in published maps and institutional affiliations.

Copyright: (c) 2022 by the authors. Licensee MDPI, Basel, Switzerland. This article is an open access article distributed under the terms and conditions of the Creative Commons Attribution (CC BY) license (https:// creativecommons.org/licenses/by/ $4.0 /)$.

\author{
Department of Interfacial Phenomena, Institute of Chemical Sciences, Faculty of Chemistry, Maria \\ Curie-Skłodowska University in Lublin (UMCS), pl. Marii Curie-Skłodowskiej 3, 20-031 Lublin, Poland; \\ terpil@umcs.pl \\ * Correspondence: e.chibowski@gmail.com
}

\begin{abstract}
Thin films of chitosan are often deposited on various surfaces to provide them with antiseptic properties. In the presented research, chitosan foils were obtained using two methods and treated with nitrogen plasma. The obtained materials were characterized by measuring the wettability of the test liquids, and the apparent surface free energy was calculated using the Tadmor equilibrium contact angles. The surface topography was characterized using optical profilometry and SEM. On the other hand, the effect of plasma on surface groups was investigated using the FTIR-ATR technique. Plasma activation of the surface increases the polarity of the surface. This is observed in the changed surface roughness and the share of functional groups on the surface.
\end{abstract}

Keywords: chitosan; plasma activation; wettability

\section{Introduction}

Chitosan films deposited on solid substrates are interesting in many aspects [1-3]. Among others, it is expected that chitosan can imparts antiseptic properties for solid supports. This would have important applications wherever such antiseptic coatings are needed. In the previous papers investigated the PEEK polymer with the deposited chitosan layers whose surface had been activated with plasma [1]. In the scientifical studies it was found that a thin polymer coating layer had not shield the interactions originating from the substrate [4]. In all the aforementioned papers, we have examined chitosan films deposited on solid substrates. In all the aforementioned papers, we have examined the chitosan films deposited on solid substrates. In this paper, we studied chitosan as the plates separated from a solid substrate polymer. In the literature there are reports on the chitosan films activated with plasma. However, different methods of plasma activation were applied [5,6], or low power generator and long activation time were used [7]. Those results are very interesting, but wettability of the surface was not studied there. Therefore it was interesting to carry out a study on the wettability of the chitosan foils and the effect of their plasma treatment using the plasma parameters applied previously [1].

\section{Materials and Methods}

Method of Chitosan Preparation

Chitosan foils were obtained by the addition of $2 \mathrm{wt} \%$ chitosan (Sigma-Aldrich, medium weight, the degree of initial deacetylation 75-85\%) solution in the acetic acid ( $3 \mathrm{wt} \%$ ) onto a glass plate followed by drying at $80^{\circ} \mathrm{C}$ for $3 \mathrm{~h}$ (Figure $1 \mathrm{~B}^{\prime}$ ), i.e., its homogenization. Plasma simply removes the top layer in this case (sample 1). 


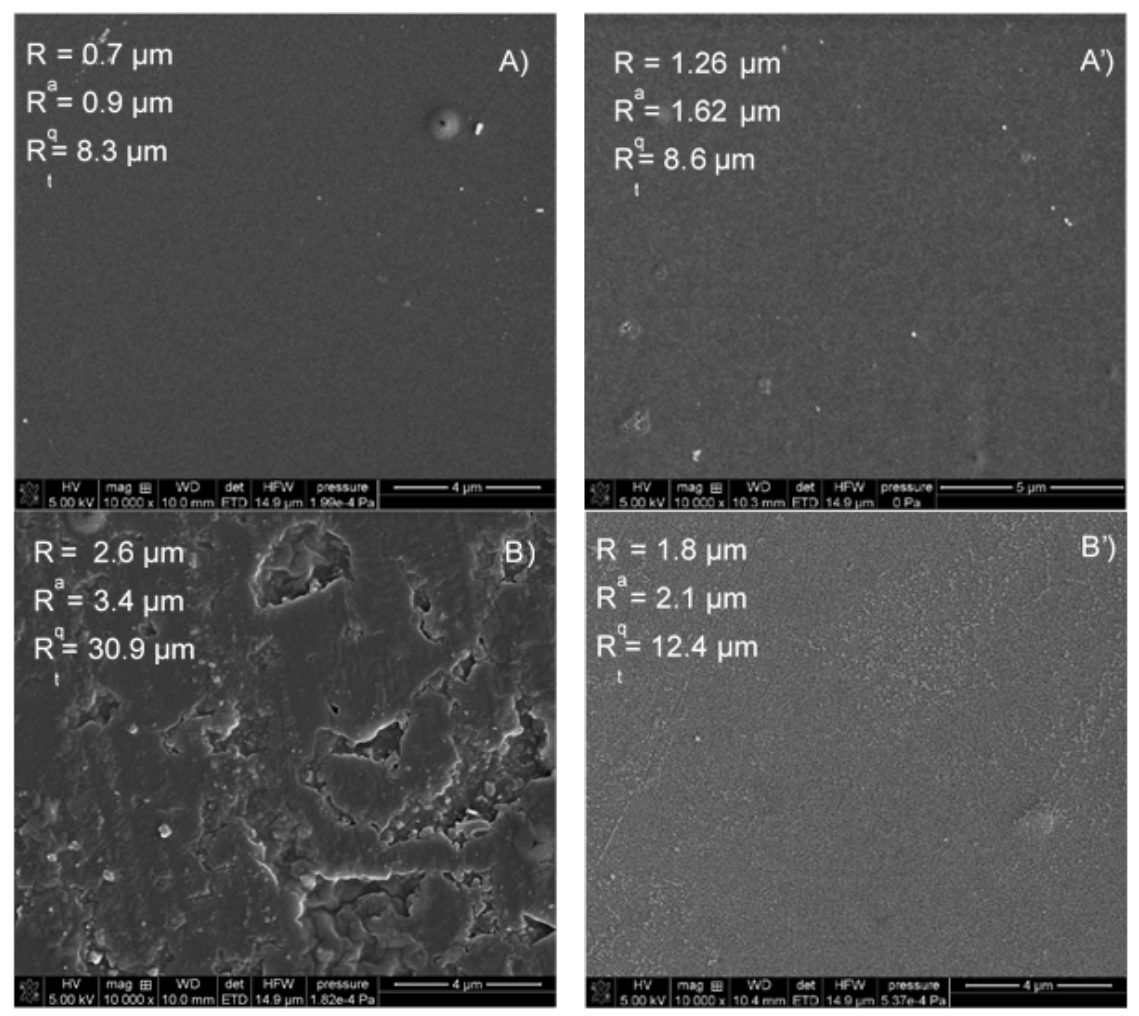

Figure 1. SEM images of chitosan foils: (A) sample $1 ;\left(\mathbf{A}^{\prime}\right)$ sample 1 treated with $\mathrm{N}_{2}$ plasma; (B) sample 2; (B') sample 2 treated with $\mathrm{N}_{2}$ plasma.

The other sample was prepared by dipping the film in a $10 \%$ aqueous solution of alkali and followed by drying. This treatment strengthens the structure due to the change in the protonation of the $\mathrm{NH}_{2}$ group of the polymer and changing the macromolecule conformations (sample 2). Before the plasma treatment the chitosan foils were separated from the glass supports, thickness of the obtained foils was about $40 \mu \mathrm{m}$ as measured by optical profilometry. The plasma duration was the same in both cases of the samples preparation.

Principles of plasma treatment, contact angle measurements and spectroscopy are described in our previous papers [1].

\section{Results}

As shown in Figure 1, the surface activation with plasma causes, depending on the method of obtaining the film, an almost twofold increase in roughness, which was confirmed by profilometric analysis (sample 1). In the case of the second sample, the surface obtained is homogeneous. The action of the plasma on the surface leads to the reduction of its roughness (Figure $1 \mathrm{~B}^{\prime}$ ), i.e., its homogenization. Plasma simply removes the top layer in this case (SEM images Sample 1 in Supplementary Materials). This leads to a decrease in the roughness of the sample. In addition to the change in surface roughness, the chemical groups on the surface of the polymer films also change. The water contact angle measured on the unmodified polymer (sample 1) was $75.1^{\circ} \pm 0.5$ while when the surface was plasma modified its value was $34.7^{\circ} \pm 0.8$. However, when the contact angles were measured on a polymer enriched with additional $-\mathrm{NH}_{2}$ groups (sample 2), the advancing contact angle of the water was $77.9^{\circ} \pm 1.6$, after modification it was $40.5^{\circ} \pm 3.1$. The contact angle hysteresis on both types of surfaces was about $10^{\circ}$. In order to calculate the apparent surface free energy components, the contact angles of the apolar diiodomethane were also measured. The advancing contact angle was $42.7^{\circ} \pm 2.9$ and $33.3^{\circ} \pm 3.6$, respectively, for the unmodified samples and modified sample, thus in the case of sample 2 the contact angle was about $10^{\circ}$ lower. After the plasma activation, the receding angle was approximately $17^{\circ}$ for both surface types. The apparent surface free energy was calculated using two 
approaches: the contact angle hysteresis (CAH) [8] and the acid base (LWAB) [9] approach using the Tadmor [10] equilibrium contact angles (Sample 2 in Supplementary Materials).

On the untreated surfaces the energy calculated from the CAH approach is about $49 \mathrm{~mJ} / \mathrm{m}^{2}$, while when the surfaces were treated with nitrogen plasma, it increases to about $70 \mathrm{~mJ} / \mathrm{m}^{2}$. The changes in the wettability of the surface of the chitosan foils are mainly due to a significant increase in the polar electron-donor parameter of the apparent surface free energy when it was calculated using the LWAB approach. In the case of sample 1, this parameter increases from $22.4 \pm 0.2 \mathrm{~mJ} / \mathrm{m}^{2}$ to $50.5 \pm 1.5 \mathrm{~mJ} / \mathrm{m}^{2}$, an even greater increase occurs in the case of sample 2, where the parameter increases from $14.5 \pm 1.1 \mathrm{~mJ} / \mathrm{m}^{2}$ to $44.3 \pm \mathrm{mJ} / \mathrm{m}^{2}$. To check how the surface chemistry changed, FTIR-AT spectra was taken.

Analyzing the spectra obtained with the FTIR-ATR technique of the case of sample 1, an decrease in the intensity of vibrations can be seen at the frequency of $3250 \mathrm{~cm}^{-1}$, which corresponds to the stretching vibration of the $\mathrm{N}-\mathrm{H}$ and $\mathrm{O}-\mathrm{H}$ bonds. This effect is not visible in the case of sample 2. Plasma surface activation does not affect the vibration intensity corresponding to the symmetrical stretching of the $-\mathrm{CH}_{3}$ group $\left(2925 \mathrm{~cm}^{-1}\right)$ [11]. At a wavelength of $1645 \mathrm{~cm}^{-1}$, there is a peak characteristic of the group vibration stretching $(\mathrm{C}=\mathrm{O}$ amide $\mathrm{I})$. In the case of an acidic sample, it is lower compared to the alkaline sample. On the other hand, the activation of the surface with plasma causes opposite effects for this group; in the case of sample 1 the intensity decreases while in the case of 2 , it increases. A similar effect can be seen in the case of the $1589 \mathrm{~cm}^{-1}$ peak corresponding to the vibrations of the N-H group. The symmetrical deformation of the $\mathrm{CH}_{2}$ and $\mathrm{CH}_{3}$ groups correspond to the peaks present at the wavelengths of $1423 \mathrm{~cm}^{-1}$ and $1375 \mathrm{~cm}^{-1}$, respectively. The plasma effect is more pronounced in the case of the second more alkaline sample. The spectra also shows the peaks characteristic of C-O stretching at 1066 and $1028 \mathrm{~cm}^{-1}$ wavelengths. As can be seen from Figure 2, the method of preparing the foil mainly affects the $\mathrm{C}=\mathrm{O}$ and N-H groups of the structure of the tested compound and plasma activation influences differently for the same polymer obtained in different ways.

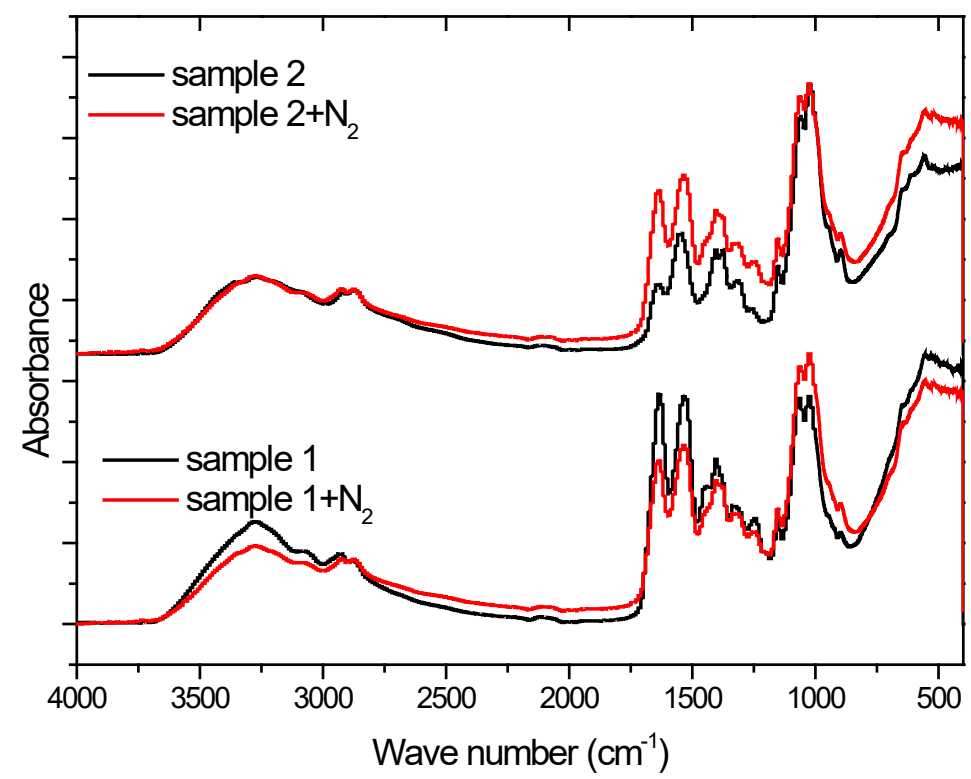

Figure 2. FTIR-ATR spectra of chitosan foils.

\section{Conclusions}

The structure of the orbital foil varies depending on the method of obtaining. The advancing water contact angles measured on the films are comparable to those measured on the chitosan layers deposited on polyetheretherketone [1]. Plasma surface activation has different effects on the resulting surfaces. In the case of the acidic, it increased the roughness, while in the case of alkaline one, the effect was opposite. The value of the 
contact angles is the result of topography and surface chemistry. The research shows that in the case of a more homogeneous surface of the first sample, surface chemistry is more responsible for the wettability of the surface, and topography in the second. If the influence of topography is eliminated due to the plasma activation, the difference in the values of the advancing contact angles is caused by a different chemical structure of the surface.

Supplementary Materials: The following are available online at https:/ /www.mdpi.com/article/10 $.3390 /$ colloids6010006/s1.

Author Contributions: Conceptualization, K.T. and E.C.; methodology, K.T.; investigation, K.T.; resources, K.T.; writing—original draft preparation, E.C.; writing—review and editing. All authors have read and agreed to the published version of the manuscript.

Funding: This research received no external funding.

Institutional Review Board Statement: Not applicable.

Informed Consent Statement: Not applicable.

Data Availability Statement: Data are available within the sources mentioned in the references as well as collected by the authors during the experiments and included in this paper (raw data can be available on request from the corresponding author).

Conflicts of Interest: The authors declare no conflict of interest.

\section{References}

1. Terpiłowski, K.; Wiącek, A.E.; Jurak, M. Influence of nitrogen plasma treatment on the wettability of polyetheretherketone and deposited chitosan layers. Adv. Polym. Technol. 2018, 37, 2166-2174. [CrossRef]

2. Molina, R.; Jovanic, P.; Vilchez, S.; Tzanov, T.; Solans, C. In situ chitosan gelation initiated by atmospheric plasma treatment. Carbohydr. Polym. 2012, 4, 2745-2749. [CrossRef] [PubMed]

3. Tkvac, T.; Petrinič, I.; Luxbacher, T.; Vesel, A.; Ristič, T.; Zemlič, L.F. Influence of $\mathrm{O}_{2}$ and $\mathrm{CO}_{2}$ plasma treatment on the depositionof chitosan onto polyethylene terephthalate (PET) surfaces. Int. J. Adhes. Adhes. 2014, 48, 168-176. [CrossRef]

4. Ozbay, S.; Erdogan, N.; Erden, F.; Ekmekcioglu, M.; Ozdemir, M.; Aygun, G.; Ozyuzer, L. Surface free energy analysis of ITO/Au/ITO multilayer thinfilms onpolycarbonate substrate by apparent contact angle measurements. Appl. Surf. Sci. 2020, 529, 147111. [CrossRef]

5. Liu, Y.; Wu, C.; Bai, Y.; Shuyu, L.; Yuan, C.; Ding, T.; Hu, Y. Effect of glow discharge plasma on surface modification of chitosan film. Int. J. Biol. Macromol. 2019, 138, 340-348. [CrossRef] [PubMed]

6. Chang, S.H.; Chian, C.H. Plasma surface modification effects on biodegradability and protein adsorption properties of chitosan films. Appl. Surf. Sci. 2013, 282, 735-740. [CrossRef]

7. Silva, S.S.; Luna, S.M.; Gomes, M.E.; Benesch, J.; Pashkuleva, I.; Mano, J.F.; Reis, R.L. Plasma Surface Modification of Chitosan Membranes: Characterisation and Preliminary Cell Response Studies. Macromol. Biosci. 2008, 8, 568-576. [CrossRef] [PubMed]

8. Chibowski, E. Contact angle hysteresis due to a film present behind the drop. In Contact Angle, Wettability and Adhesion, 2nd ed.; Mittal, K.L., Ed.; VSP: Utrecht, The Netherlands, 2002; Volume 2, pp. 265-288.

9. Van Oss, C.J.; Good, R.J.; Chaudhury, M.K. The role of van der Waals forces and hydrogen bonds in "hydrophobic interactions" between biopolymers and low energy surfaces. J. Colloid Interface Sci. 1986, 111, 378-390. [CrossRef]

10. Tadmor, R. Line energy and the relation between advancing, receding, and young contact angles. Langmuir 2004, 20, 7659-7664. [CrossRef] [PubMed]

11. Fernandes Queiroz, M.; Teodosio Melo, K.R.; Araujo Sabry, D.; Lanzi Sassaki, G.; Oliveira Rocha, H.A. Does the Use of Chitosan Contribute to Oxalate Kidney Stone Formation? Mar. Drugs 2015, 13, 141-158. [CrossRef] [PubMed] 